\title{
The Discolouration of Human Teeth from Archaeological Contexts: Elemental Analysis of a Black Tooth from a Roman Cranium Recovered from the River Witham, Lincoln, UK
}

\author{
Emma L. Brown, ${ }^{1}$ Ronald A. Dixon, ${ }^{2}$ and Jason W. Birkett ${ }^{3}$ \\ ${ }^{1}$ Archaeological Sciences, University of Bradford, Richmond Road, Bradford, West Yorkshire, BD7 1DP, UK \\ ${ }^{2}$ School of Life Sciences, University of Lincoln, Brayford Pool, Lincoln, LN6 7TS, UK \\ ${ }^{3}$ School of Pharmacy and Biomolecular Sciences, Liverpool John Moores University, James Parsons Building, Byrom Street, \\ Liverpool, L3 3AF, UK
}

Correspondence should be addressed to Jason W. Birkett; j.w.birkett@ljmu.ac.uk

Received 23 June 2014; Accepted 13 August 2014; Published 14 September 2014

Academic Editor: Hugo Cardoso

Copyright (C) 2014 Emma L. Brown et al. This is an open access article distributed under the Creative Commons Attribution License, which permits unrestricted use, distribution, and reproduction in any medium, provided the original work is properly cited.

A human cranium was recovered from the River Witham, Lincoln, UK, at Stamp End Lock during a police operation in 2002. Although extensive trauma was noted, the skull was not of forensic interest since radiocarbon dating revealed that the individual had lived during the Roman occupation of Lincoln, almost 2,000 years ago. The skull had unusual black "metallic" staining on the occlusal surfaces of the teeth. As this kind of staining is relatively uncommon, it was investigated to determine the possible cause. An individual tooth was subjected to two elemental analyses: inductively coupled plasma-atomic emission spectroscopy (ICP-AES) and scanning electron microscopy-energy dispersive X-ray analysis (SEM-EDX). A small sample $(n=21)$ of modern teeth was also analysed for comparison to determine "normal" ranges of certain elements. Analysis of the ancient tooth shows very high levels of manganese $(275 \mu \mathrm{g} / \mathrm{g})$ and iron $(1540 \mu \mathrm{g} / \mathrm{g})$ compared to modern teeth values $(1.90 \mu \mathrm{g} / \mathrm{g} \mathrm{Mn}$ and $40.81 \mu \mathrm{g} / \mathrm{g}$ Fe). These results were consistent with the black staining arising from iron and manganese infiltrating bone and dental tissue from the depositional environment, and not a consequence of diet, pathological process or cultural practices.

\section{Introduction}

There are many reported cases of discoloured teeth from both living and deceased individuals in the scientific literature. In living individuals, tooth discolouration is a well characterised feature of some diseases, medical treatments, cultural practices, and occupations, whilst discoloured teeth in deceased individuals may be due to the action of fungi, interaction with the burial environment, or a visual marker of a habit during life.

A number of metabolic and congenital conditions cause human teeth to become discoloured; for instance, fluorosis causes brown staining of the teeth and purple staining of the gums, whilst congenital erythropoietic porphyria can produce red-purple dentition $[1,2]$. Discoloured dentition is also associated with some occupations-most notably workers in the metal industry, where a variety of staining has been reported $[3,4]$. Certain habits, such as smoking and chewing tobacco and drinking coffee, are known to cause yellow-brown discolouration of dentition $[5,6]$, whilst chewing betel nut produces a deep red staining of the dentition and oral mucosa [7]. Some drug treatments are also known to cause dental discolouration; for example, the antibiotic tetracycline is well documented as causing black discolouration of dentition $[8,9]$.

Deliberate staining of teeth as a form of body modification has a long history in a number of Asian cultures. For example, in Japan, women stained their teeth black using an acidic mixture containing iron compounds, resulting in an even black stain. This practice was known as ohaguro and was practiced until the beginning of the 20th century [10]. In addition, people from southeast Asia and China have employed a diverse range of plants to stain their teeth dating back as far as the Neolithic, some 4500 years ago [11]. 
Discoloured dentition has also been noted on the dentition of deceased individuals. A black metallic stain on the teeth of Dr. Carl Weiss was discovered when he was exhumed after 61 years. Dr. Weiss was shot repeatedly during an alleged assassination of the Governor of Louisiana in 1935. A subsequent analysis by scanning electron microscopy techniques (SEM-EDX) showed the presence of mercury in the teeth, but nowhere else in the remains. The investigators concluded that the black staining was from dental restorations that had degraded. They postulate that products of decomposition may have triggered the release of mercury from mercury amalgam restorations. They suggested that sulphur dioxide in combination with the humid burial environment may have produced sulphuric acid, which reacted with the amalgam causing the staining [12].

A number of authors have reported the occurrence of pink teeth in both forensic and archaeological contexts. In forensic contexts, pink teeth may be associated with those who died as a result of trauma or instances of drowning $[13,14]$. However, the pink colouration has been identified as haemoglobin, and it thought to be caused by seepage of haemoglobin or its derivatives into dentinal tubules $[13,15,16]$ and as such could be expected to occur in every death. Dye et al. [16] sectioned a number of teeth from individuals buried at a Medieval leprosarium in Chichester, UK. Whilst the teeth bore a resemblance to pink teeth in forensic cases, the authors noted that the cause of pink staining in archaeological teeth was probably related to postmortem change brought about by saprophytic fungi.

Green discolouration of teeth and bone was noted in Spanish and Basque skeletons from the Cathedral of Santa Maria in Vitoria, Spain. The green stain was the result of an ancient practice that involved placing a silver or gold coin containing bronze in the mouth of the deceased prior to burial for the purpose of paying the boatman for passage across the river of woe. The copper component of the bronze reacted with the acidic environment caused by decomposition creating basic copper carbonate. The copper carbonate then seeped into the porous spaces of the bones and teeth or replaced the mineral portion of the bone [17].

Blue teeth have been reported in subadult skeletons affiliated with the Mexica cultural group at Tlatelolco [18]. The site was occupied from around AD 1340 until the arrival of the Spanish in the 16th century. A total of 1592 teeth were observed in 148 individuals: 74 (4.65\%) had a blue discolouration. The authors investigated the staining using particle induced X-ray emission spectrometry (PIXE). They found high levels of manganese and iron that could not be a result of live ingestion, as internal processes of absorption and excretion would have controlled the levels of these elements [19].

A blue-black metallic discolouration was noted on the dentition of individuals buried in a Medieval (c AD 11001600) churchyard in Trondheim, Norway. A total of 51 skulls were found to have unusual discolouration on the occlusal surfaces of the teeth, similar to the teeth in the cranium from the River Witham [20, 21]. The majority of skulls with black teeth were discovered in waterlogged soil rich in organic content. Trace element analysis using secondary ion mass

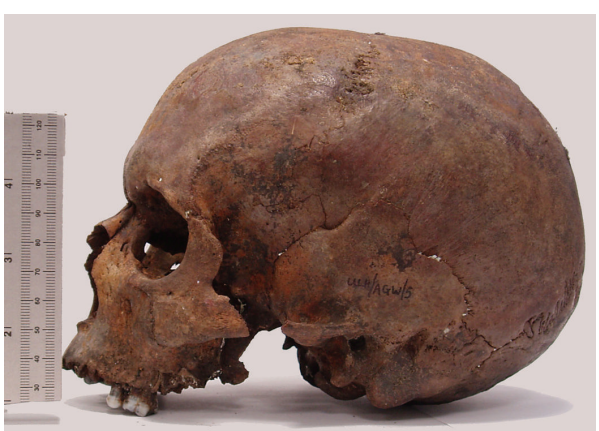

FIGURE 1: The cranium of an adult male recovered from the River Witham, Lincoln, UK.

spectrometry (SIMS) and atomic absorption spectroscopy (AAS) was used to determine the elevated levels of metals. Manganese, strontium, barium, and iron were selected for further analysis with AAS, as these elements correlated with the analysed path (tooth section) and degree of colouration. Manganese showed the strongest correspondence with the discoloured enamel.

In this study, the cranium recovered from the River Witham in Lincoln exhibited a black metallic staining on the surfaces of the teeth. As this black staining is relatively uncommon and there are few instances of it being reported in the literature, it was considered worthy of further investigation to determine the cause of the staining.

\section{Materials and Methods}

2.1. The Witham Cranium. A human cranium was recovered from the surficial $(0-10 \mathrm{~cm})$ sediment in Stamp End Lock (SK982711), Lincoln, UK, by police during a murder investigation in 2002. The cranium (Figure 1) was unrelated to the enquiry and no other remains were found which could be associated with the same individual. After examination by a forensic pathologist, the skull was determined to have no forensic significance for further investigation by law enforcement agencies, despite evidence of massive perimortem trauma. A sample approximately $3 \mathrm{~cm}$ square was taken from the occipital bone, just posterior to the foramen magnum and sent for AMS radiocarbon dating at the 14 CHRONO Centre at Queens University, Belfast.

This analysis gave an age of $1858 \pm 35$ years (calibrated using OxCal 4.2 and the INTCAL09 data set at $95.4 \%$ probability $76-237 \mathrm{cal} A D)$. This date is consistent with the Roman occupation of Lincoln [22].

The cranium was that of an adult male, indicated by the large mastoid processes, prominent supraorbital ridges, temporal ridges, and nuchal crest [23] (see Figure 1). The third molar was fully erupted with fully formed roots, suggesting a minimum age at death in the early 20s [24].

There were seven teeth present in the maxilla, all of which exhibited metallic blue-black staining on the occlusal surfaces (see Figure 2). When a tooth was extracted for analysis, it was noted that the intact root was also stained black. The stain was uniform and could not be scraped off. Due to the historic nature of the skull and in order to preserve it as much 


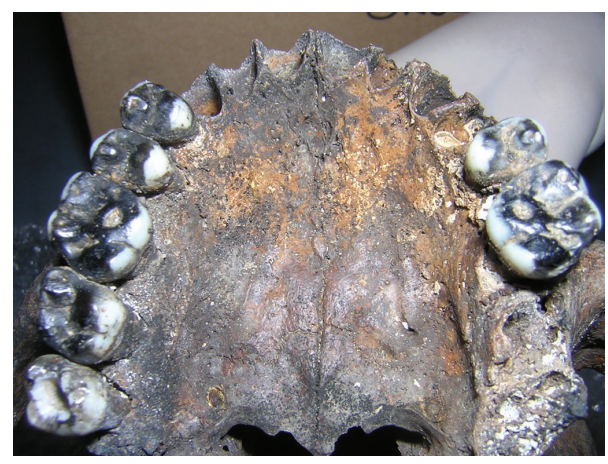

FIGURE 2: The maxilla of the Witham cranium showing metallic black staining on the occlusal surfaces of the seven teeth.

as possible, only one tooth was extracted for the analysis described in this work. No X-rays were performed.

2.2. Modern Tooth Samples. Twenty-one modern adult teeth were obtained from anonymous donors undergoing routine extractions after informed consent and with permission from a dental surgery in Nottingham, UK. Patients were given information about the study, its aims and objectives, before consenting to donation of their tooth. Approval was sought and granted by the University of Lincoln's ethics committee prior to undertaking this collection. Both males and females donated teeth, and all types of teeth were collected from both the maxilla and mandible. Some teeth with dental caries $(10 \%)$ were included in the sample.

2.3. Preparation and Analysis of Tooth Samples. To prevent sample contamination, all laboratory glassware was cleaned with detergent (5\% (v/v) Decon 90 solution) and deionised water then rinsed with $10 \%(\mathrm{v} / \mathrm{v})$ Analar nitric acid, then rinsed with deionised water before use. Each tooth was soaked in a solution of $10 \%(\mathrm{v} / \mathrm{v})$ hydrogen peroxide for 1 hour to remove any organic material, although some of the modern teeth had been sterilised by the dental surgeon using sodium hypochlorite. They were then rinsed with deionised water, air dried, and weighed. The teeth were digested with Aristar reagents, using $4 \mathrm{~mL}$ of $70 \%(\mathrm{v} / \mathrm{v})$ nitric acid and $3 \mathrm{~mL} 70 \%$ $(\mathrm{v} / \mathrm{v})$ perchloric acid in a conical flask, heated on a hotplate in a fume cupboard until a transparent liquid was produced which was adjusted to $10 \mathrm{~mL}$ with deionised water. Blanks were included with the sample digestions. Concentrations of metals in the modern tooth samples were determined with Atomic Absorption Spectrometer (Unicam 969 AA Spectrometer, Thermo Electron Corporation) in flame mode. Based on the literature $[18,20,21,25]$ the following metals were selected for analysis as they have been implicated in the cause of the colouration of teeth and bone: Manganese, Iron, Zinc, and Lead. All reagents and material were purchased from Sigma Aldrich (Gillingham, UK).

The ancient tooth was cleaned, weighed, and digested as previously described. In order to use the minimum amount of sample digest possible yet enabling simultaneous quantification of multiple elements, the metal content $(\mathrm{Mn}$,

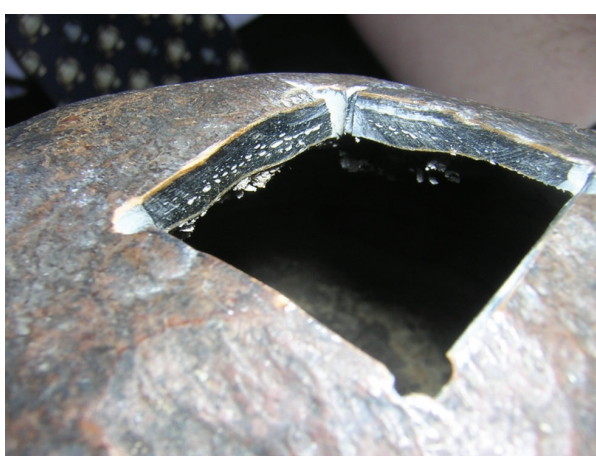

FIgURE 3: Structure of the diploë in the Witham cranium illustrating the cortical (dark brown) and trabecular bone (filled with blue-black material).

$\mathrm{Fe}, \mathrm{Zn}, \mathrm{Pb})$ of the ancient tooth was determined using an ICPAES (Perkin Elmer Optima 2100 DV OES).

For SEM-EDX analysis, a powdered tooth sample taken from the right maxillary 3rd molar of the ancient cranium was analysed and visualised using a Quanta 200 ESEM (FEI, Eindhoven) and an Oxford Instruments X-Act dry X-ray detector at $20 \mathrm{KeV}$ and a working distance of $10 \mathrm{~mm}$ (usual angle of $30^{\circ}$ ). The analysis of the powder was carried out for 100 seconds at a minimum count rate of $1000 \mathrm{cps}$, giving the subsequent quantitative results. This was carried out using the Inca software package point and analysis provided by Oxford Instruments.

\section{Results and Discussion}

Table 1 shows the results from the analysis of a set of 21 modern teeth and the ancient tooth. The results of the modern teeth are observed to be similar to other modern teeth data sets from other authors [26-28]. The ancient tooth has very large amounts of iron and manganese compared to the mean concentration of the metals detected in modern teeth. Further comparison of the ancient and modern tooth data reveals that the level of lead produced similar results. The level of zinc is low compared to modern teeth, with zinc levels $3 x$ higher in the modern teeth set. The levels of zinc in human tissue are known to be associated with nutritional conditions [29], with some authors suggesting that zinc plays a crucial role in bone growth and regeneration [30]. Increases in the content of zinc in the modern teeth are probably associated with an increase in the consumption of zinc-rich foods, such as meat protein [27], although it should be noted that zinc has yielded inconsistent trophic level effects and is thought to not be a reliable indicator of trophic level [31].

When the right maxillary third molar was removed from the ancient skull it was noted that the root was stained black, as was the occlusal surface of the tooth. It is also interesting to note that when the bone sample for radiocarbon dating was taken, the diploë had been extensively recrystallised with a material similar in appearance to the blue-black material of the tooth (see Figure 3). The laboratory that carried out the radiocarbon dating also encountered some difficulty in obtaining enough collagen from the bone sample submitted 


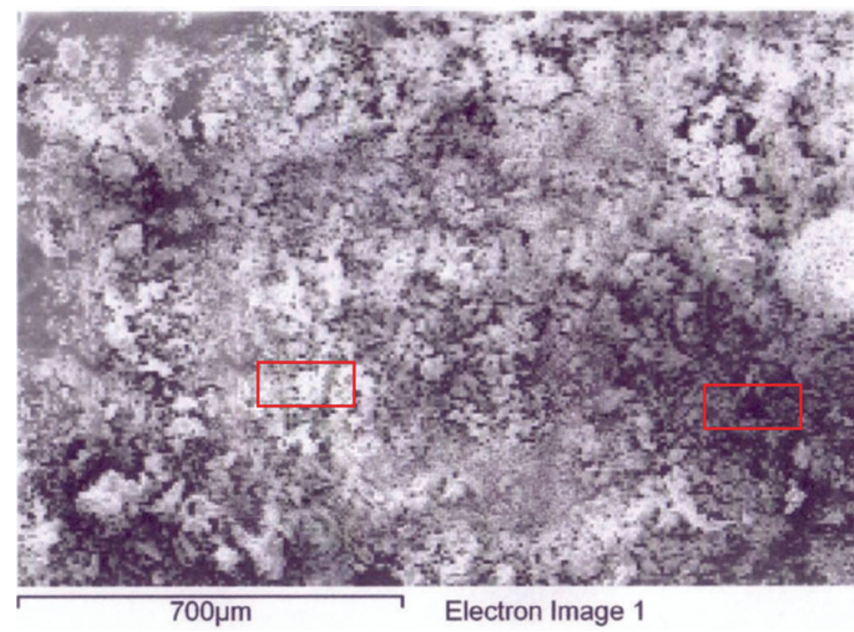

FIGURE 4: SEM scan of powdered ancient tooth material illustrating light (scan 1) and dark (scan 2) material.

TABLE 1: Metal concentrations of a set of modern teeth and the ancient tooth in $\mu \mathrm{g} / \mathrm{g}$.

\begin{tabular}{|c|c|c|c|c|}
\hline & $\mathrm{Mn}$ & $\mathrm{Fe}$ & $\mathrm{Zn}$ & $\mathrm{Pb}$ \\
\hline \multicolumn{5}{|c|}{$\mu \mathrm{g}$ metal/g modern tooth (determined by AAS) $n=21$} \\
\hline Min & 0.88 & 20.20 & 129.02 & 0.97 \\
\hline Mean & 1.90 & 40.81 & 174.32 & 2.46 \\
\hline Max & 4.29 & 86.17 & 263.94 & 9.11 \\
\hline StDev & 0.67 & 19.52 & 34.03 & 2.09 \\
\hline \multicolumn{5}{|c|}{$\mu \mathrm{g}$ metal/g ancient tooth (determined by ICP-AES) $n=1$} \\
\hline Mean & 275.24 & 1539.72 & 62.60 & 2.40 \\
\hline StDev & 1.09 & 0.66 & 0.79 & 2.34 \\
\hline
\end{tabular}

to them. This is suggestive of significant postmortem change including the loss of the organic component of bone. The blue-black metallic stain present on the teeth and within the internal structure of the bone suggests that material from the depositional environment had infiltrated both bone and teeth.

The descriptions of the stained teeth from the medieval churchyard in Trondheim were very similar to the teeth from the Witham cranium. Elemental analysis of these teeth revealed high levels of manganese and iron [20, 21]. The results presented here show that the teeth from the Witham cranium also had high levels of manganese and iron.

As it appears that manganese compounds may be responsible for the black staining, it was crucial that the teeth were analysed for manganese to establish a "normal" range in a contemporary population to compare with the ancient tooth. Both manganese and iron in the ancient tooth are clearly higher, with manganese concentrations 140x greater than modern teeth and concentrations for iron $38 x$ greater. These high levels of these metals present in the Witham cranium tooth are in concordance with other studies on discoloured teeth which found that iron and manganese in various forms caused blue, brown, and black staining on archaeological teeth.

The study of Mansilla et al. [18] on blue stained teeth suggests that the postmortem alterations to teeth involved the cumulation and diagenesis of iron, manganese, and organic matter solutions that were eluviated from the soil. An earlier study of subadult dentition from 92 individuals from sites around Mexico City (Templo Mayor, Tlatelolco, and Metropolitan Cathedral) revealed eight individuals with blue staining on the teeth. Subsequent analysis of the stained teeth using PIXE and Rutherford Backscattering Spectrometry (RBS) found higher levels of manganese and iron in the stained sections of teeth compared to nonstained teeth [25].

Work by Stermer and co-workers [20, 21] demonstrated there was no difference in the amount of iron in white and black enamel on the Trondheim Churchyard black teeth, suggesting that manganese caused the black staining. StermerBeyer-Olsen and Risnes [20] believed that the staining was caused by factors in soil and in their follow-up study [21] concluded that it was manganese oxide deposited from grave soil that was the cause of the blackish staining. More specifically, they suggested that since manganese does not occur free in nature, it must be present within teeth as a mineral such as pyrolusite (manganese dioxide) and psilomelane (an oxide mineral of manganese and barium), both of which are described as bluish-black with a metallic appearance. These minerals form as precipitates in lakes and bogs [32-34].

The powdered ancient tooth was analysed using SEMEDX (Figure 4) which illustrates areas of both light and dark material. The first scan was of an area of white powder, 
TABLE 2: Elements detected in powdered tooth material by SEM-EDX.

\begin{tabular}{|c|c|c|c|c|}
\hline \multirow{2}{*}{ Element } & \multicolumn{2}{|c|}{ Scan 1 (light tooth material) } & \multicolumn{2}{|c|}{ Scan 2 (dark tooth material) } \\
\hline & Weight $\%$ & Atomic\% & Weight $\%$ & Atomic\% \\
\hline $\mathrm{C}$ & 16.22 & 26.03 & 8.57 & 15.04 \\
\hline $\mathrm{O}$ & 44.20 & 53.26 & 44.48 & 58.64 \\
\hline $\mathrm{Na}$ & 0.34 & 0.29 & 0.40 & 0.37 \\
\hline $\mathrm{Mg}$ & 0.14 & 0.11 & 0.18 & 0.16 \\
\hline $\mathrm{Al}$ & 0.06 & 0.04 & 0.07 & 0.06 \\
\hline $\mathrm{P}$ & 11.69 & 7.28 & 13.33 & 9.08 \\
\hline $\mathrm{Cl}$ & 0.14 & 0.07 & 0.15 & 0.09 \\
\hline $\mathrm{Ca}$ & 26.32 & 12.66 & 30.60 & 16.10 \\
\hline $\mathrm{Fe}$ & 0.30 & 0.11 & 0.48 & 0.18 \\
\hline $\mathrm{Cu}$ & 0.31 & 0.09 & 0.28 & 0.09 \\
\hline $\mathrm{Sn}$ & 0.28 & 0.05 & 0.46 & 0.08 \\
\hline $\mathrm{Pt}$ & - & - & 0.99 & 0.11 \\
\hline
\end{tabular}

which was most likely to be tooth material that was largely unaffected by the staining. The results (Table 2) indicate large amounts of carbon, oxygen, phosphorous, and calcium, entirely consistent with the composition of hydroxyapatite $\mathrm{Ca}_{10} \mathrm{~F}_{2}\left(\mathrm{PO}_{4}\right)_{6}$. The second scan was from the area of darker material. Most noticeably there is a large decrease in the amount of carbon. This may indicate an overall decrease of the organic component of the tooth, which is evidence of diagenesis, a complex set of processes that may involve the processes of dissolution, precipitation, mineral replacement, recrystallisation, and ionic substitution [35-37].

The loss of organic content combined with evidence of the infiltration of elements from the depositional environment has been reported by a number of authors. Garland [38] defined infiltrations as the "presence of extraneous material within the bone substance itself" and noted that these infiltrations are often visible on bone sections. Manganese and iron compounds have been implicated as infiltrants in archaeological bone resulting in black staining, specifically framboidal pyrite (crystals of iron sulphide, $\mathrm{FeS}_{2}$ ) and manganese oxides [39-46].

Water is also likely to be a key factor in diagenetic processes, but as Hedges [35] states, the effect of hydrology on diagenetic processes is complicated. In water with acidic $\mathrm{pH}$, calcium phosphates in bone become more soluble. In acidic conditions, manganese and iron compounds are soluble. This, in combination with humic substances in water, results in brown colouration of bones in these conditions $[44,47,48]$. The cranium from the River Witham represents an extreme case of diagenetic change, with infiltration of manganese and iron resulting in the infilling of the diploë in the cranium and extensive infiltration and discolouration of the dentine of the teeth. Based on the analyses and what is known about diagenesis of manganese and iron in aquatic environments, it is suggested that this extreme taphonomic alteration of archaeological tooth and bone is caused by iron and manganese compounds present in the depositional environment.

\section{Conclusion}

Many factors and processes can cause discoloured teeth in living and deceased individuals. In the case of the Witham cranium, it has been shown that there are high levels of manganese and iron compounds present within the tooth matrix. It would appear that these compounds are responsible for the generation of the unusual black metallic staining observed.

The SEM-EDX results show less carbon in the darker areas of the tooth. This, together with the ICP-AES results from the metal analysis, suggests that the cranium has undergone significant postmortem change. This will have involved a complex set of processes characterised by the loss of the organic component of the teeth and diagenesis of manganese and iron compounds from the depositional environment and is not the result of pathological processes, cultural practice, or diet.

\section{Conflict of Interests}

The authors declare that there is no conflict of interests regarding the publication of this paper.

\section{Acknowledgments}

The authors would like to thank the School of Life Sciences at the University of Lincoln for financial support to carry out this research. The authors also wish to thank Dr. Bill Hayes and Mr. Mathieu Elie for technical support and two anonymous Dental Surgeons and their patients for providing teeth for this project.

\section{References}

[1] M. M. D. Kooijman and H. S. Brand, "Oral aspects of porphyria," International Dental Journal, vol. 55, no. 2, pp. 61-66, 2005. 
[2] A. Watts and M. Addy, "Tooth discolouration and staining: a review of the literature," British Dental Journal, vol. 190, pp. 309316, 2001.

[3] G. Berman, M. Bush, P. Bush, A. Freeman, P. Loomis, and R. Miller, "Dental identification," in Manual of Forensic Odontology, C. Bowers and G. L. Bell, Eds., pp. 75-128, CRC Press, Boca Raton, Fla, USA, 5th edition, 2013.

[4] B. N. Gupta, "Occupational diseases of teeth," Journal of the Society of Occupational Medicine, vol. 40, no. 4, pp. 149-152, 1990.

[5] H. M. Eriksen and H. Nordbø, "Extrinsic discoloration of teeth," Journal of Clinical Periodontology, vol. 5, no. 4, pp. 229-236, 1978.

[6] I. A. Pretty and L. D. Addy, "Associated postmortem dental findings as an aid to personal identification," Science and Justice, vol. 42, no. 2, pp. 65-74, 2002.

[7] B. S. Nelson and B. Heischober, "Betel nut: a common drug used by naturalized citizens from India, Far East Asia, and the South Pacific Islands," Annals of Emergency Medicine, vol. 34, no. 2, pp. 238-243, 1999.

[8] S. Q. Cohlan, “Tetracycline staining of teeth," Teratology, vol. 15, no. 1, pp. 127-129, 1977.

[9] C. J. Tredwin, C. Scully, and J.-V. Bagan-Sebastian, "Druginduced disorders of teeth," Journal of Dental Research, vol. 84, no. 7, pp. 596-602, 2005.

[10] S. Ai, T. Ishikawa, and A. Seino, “'Ohaguro” traditional tooth staining custom in Japan," International Dental Journal, vol. 15, no. 4, pp. 426-441, 1965.

[11] T. J. Zumbroich, “Teeth as black as a bumble bee's wings: the ethnobotany of teeth blackening in Southeast Asia," Ethnobotany Research and Applications, vol. 7, pp. 381-398, 2009.

[12] D. H. Ubelaker, "The remains of Dr. Carl Austin Weiss: anthropological analysis," Journal of Forensic Sciences, vol. 41, no. 1, pp. 60-79, 1996.

[13] H. Borrman, A. Chesne, and B. Brinkmann, "Medico-legal aspects of postmortem pink teeth," International Journal of Legal Medicine, vol. 106, no. 5, pp. 225-231, 1994.

[14] N. Brøndum and J. Simonsen, "Postmortem red coloration of teeth. A retrospective investigation of 26 cases," American Journal of Forensic Medicine and Pathology, vol. 8, no. 2, pp. 127130, 1987.

[15] C. W. van Wyk, "Postmortem pink teeth. Histochemical identification of the causative pigment," American Journal of Forensic Medicine and Pathology, vol. 10, no. 2, pp. 134-139, 1989.

[16] T. J. Dye, D. Lucy, and A. M. Pollard, "The occurrence and implications of post-mortem "pink teeth" in forensic and archaeological cases," International Journal of Osteoarchaelogy, vol. 5, pp. 339-348, 1995.

[17] K. A. Hopkinson, S. M. Yeats, and G. R. Scott, "For whom the coin tolls: green stained teeth and jaws in medieval and postmedieval Spanish burials," Dental Anthropology, vol. 21, pp. 12$17,2008$.

[18] J. Mansilla, C. Solis, M. E. Chávez-Lomeli, and J. E. Gama, "Analysis of colored teeth from Precolumbian tlatelolco: postmortem transformation or intravitam processes?" American Journal of Physical Anthropology, vol. 120, no. 1, pp. 73-82, 2003.

[19] M. K. Sandford, "Understanding the biogenetic-diagenetic continuum: interpreting elemental concentrations of archaeological bone," in Investigations of Ancient Human Tissue, M. K. Sandford, Ed., pp. 3-57, Gordon and Breach Science, Amsterdam, The Netherlands, 1993.
[20] E. M. Beyer-Olsen and S. Risnes, "Occurrence and distribution of blackish staining on the crowns of human teeth obtained from an archeological excavation of a medieval site in Norway," European Journal of Oral Sciences, vol. 101, no. 2, pp. 65-71, 1993.

[21] E. M. Stermer, S. Risnes, and P. M. Fischer, "Trace element analysis of blackish staining on the crowns of human archaeological teeth," European Journal of Oral Sciences, vol. 104, no. 3, pp. 253261, 1996.

[22] M. J. Jones, Roman Lincoln: Conquest, Colony and Capital, The History Press, Stroud, UK, 2002.

[23] J. Buikstra and D. Ubelaker, Standards for Data Collection from Human Skeletal Remains, Arkansas Archaeological Survey, Fayetteville, Fayetteville, Ark, USA, 1994.

[24] C. F. Moorrees, E. A. Fanning, and E. E. Hunt, "Age variation of formation stages for ten permanent teeth," Journal of Dental Research, vol. 42, pp. 1490-1502, 1963.

[25] L. Rodríguez-Fernández, J. L. Ruvalcaba-Sil, M. A. OntalbaSalamanca et al., "Ion beam analysis of ancient Mexican colored teeth from archaeological sites in Mexico City," Nuclear Instruments and Methods in Physics Research B, vol. 150, no. 1-4, pp. 663-666, 1999.

[26] M. A. Amr and A. F. I. Helal, "Analysis of trace elements in teeth by ICP-MS: implications for caries," Journal of Physical Science, vol. 21, pp. 1-12, 2010.

[27] A. Koizumi, M. Azechi, K. Shirasawa et al., "Reconstruction of human exposure to heavy metals using synchrotron radiation microbeams in prehistoric and modern humans," Environmental Health and Preventive Medicine, vol. 14, no. 1, pp. 52-59, 2009.

[28] F. C. Peedikayil, S. V. Kumar, and M. Thangavelu, "Estimation of trace elements in sound and carious enamel of primary teeth by atomic emission spectrometry," Health Sciences, vol. 2, pp. 1-11, 2013.

[29] N. Krebs and J. Westcott, "Zinc and breastfed infants: if and when is there a risk of deficiency?" in Integrating Population Outcomes, Biological Mechanisms and Research Methods in the Study of Human Milk and Lactation, M. Davis, C. Isaacs, A. Hanso, and L. Wright, Eds., vol. 503 of Advances in Experimental Medicine and Biology, pp. 69-75, Springer, 2002.

[30] T. Fukada, S. Hojyo, and T. Furuichi, "Zinc signal: a new player in osteobiology," Journal of Bone and Mineral Metabolism, vol. 31, no. 2, pp. 129-135, 2013.

[31] A. E. Dolphin and A. H. Goodman, "Maternal diets, nutritional status, and zinc in contemporary Mexican infants' teeth: implications for reconstructing paleodiets," American Journal of Physical Anthropology, vol. 140, no. 3, pp. 399-409, 2009.

[32] E. Callaghan and H. E. Thomas, "Manganese in a thermal spring in West-Central Utah," Economic Geology, vol. 34, no. 8, pp. 905-920, 1939.

[33] U. Förstner, "Accumulative phases for heavy metals in limnic sediments," in Sediment/Freshwater Interaction, P. Sly, Ed., pp. 269-284, Springer, Amsterdam, The Netherlands, 1982.

[34] M. Schoettle and G. M. Friedman, "Fresh water iron-manganese nodules in Lake George, New York," Bulletin of the Geological Society of America, vol. 82, no. 1, pp. 101-110, 1971.

[35] R. E. M. Hedges, "Bone diagenesis: an overview of processes," Archaeometry, vol. 44, no. 3, pp. 319-328, 2002.

[36] M. J. Kohn, M. J. Schoeninger, and W. W. Barker, "Altered states: effects of diagenesis on fossil tooth chemistry," Geochimica et Cosmochimica Acta, vol. 63, no. 18, pp. 2737-2747, 1999.

[37] F. D. Pate and J. T. Hutton, "The use of soil chemistry data to address post-mortem diagenesis in bone mineral," Journal of Archaeological Science, vol. 15, no. 6, pp. 729-739, 1988. 
[38] A. N. Garland, "Microscopical analysis of fossil bone," Applied Geochemistry, vol. 4, no. 3, pp. 215-229, 1989.

[39] T. A. Elliott and G. W. Grime, "Examining the diagenetic alteration of human bone material from a range of archaeological burial sites using nuclear microscopy," Nuclear Instruments and Methods in Physics Research B, vol. 77, no. 1-4, pp. 537-547, 1993.

[40] D. M. Greenlee and R. C. Dunnell, "Understanding postdepositional processes through electron microbeam analysis of archaeological bone from Se Missouri," Materials Research Society Proceedings, vol. 267, pp. 883-888, 1992.

[41] H. I. Hollund, M. M. E. Jans, M. J. Collins, H. Kars, I. Joosten, and S. M. Kars, "What happened here? Bone histology as a tool in decoding the postmortem histories of archaeological bone from Castricum, The Netherlands," International Journal of Osteoarchaelogy, vol. 22, no. 5, pp. 537-548, 2012.

[42] H.-U. Pfretzschner, "Fossilization of Haversian bone in aquatic environments," Comptes Rendus Palevol, vol. 3, no. 6-7, pp. 605616, 2004.

[43] I. Reiche and E. Chalmin, "Synchrotron radiation and cultural heritage: combined XANES/XRF study at Mn K-edge of blue, grey or black coloured palaeontological and archaeological bone material," Journal of Analytical Atomic Spectrometry, vol. 23, no. 6, pp. 799-806, 2008.

[44] R. Shahack-Gross, O. Bar-Yosef, and S. Weiner, "Black-coloured bones in Hayonim Cave, Israel: differentiating between burning and oxide staining," Journal of Archaeological Science, vol. 24, no. 5, pp. 439-446, 1997.

[45] G. Turner-Walker, "Pyrite and bone diagenesis in terrestrial sedements: evidence from the West Runton freshwater bed," Bulletin of the Geological Society of Norfolk, vol. 48, pp. 3-26, 1998.

[46] G. Turner-Walker and M. Jans, "Reconstructing taphonomic histories using histological analysis," Palaeogeography, Palaeoclimatology, Palaeoecology, vol. 266, no. 3-4, pp. 227-235, 2008.

[47] G. Turner-Walker, "The chemical and microbial degradation of bone and teeth," in Advances in Human Palaeopathology, S. Mays and R. Pinhasi, Eds., pp. 3-29, John Wiley \& Sons, Chichester, UK, 2008.

[48] G. J. van Klinken and R. E. M. Hedges, "Experiments on collagen-humic interactions: speed of humic uptake, and effects of diverse chemical treatments," Journal of Archaeological Science, vol. 22, no. 2, pp. 263-270, 1995. 

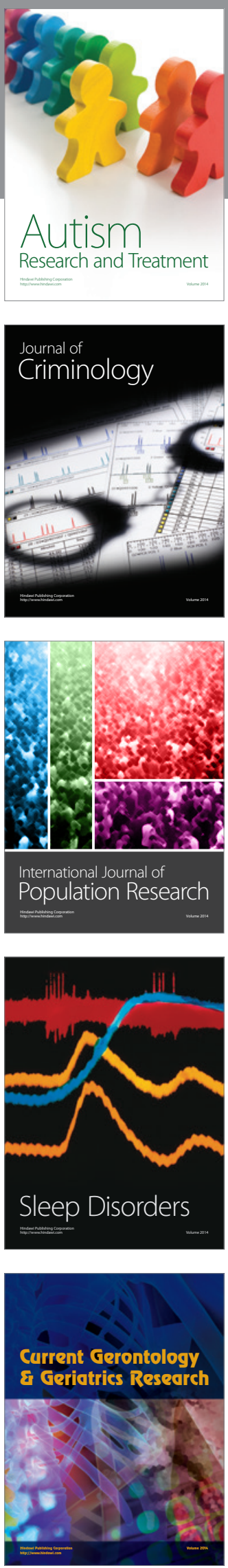
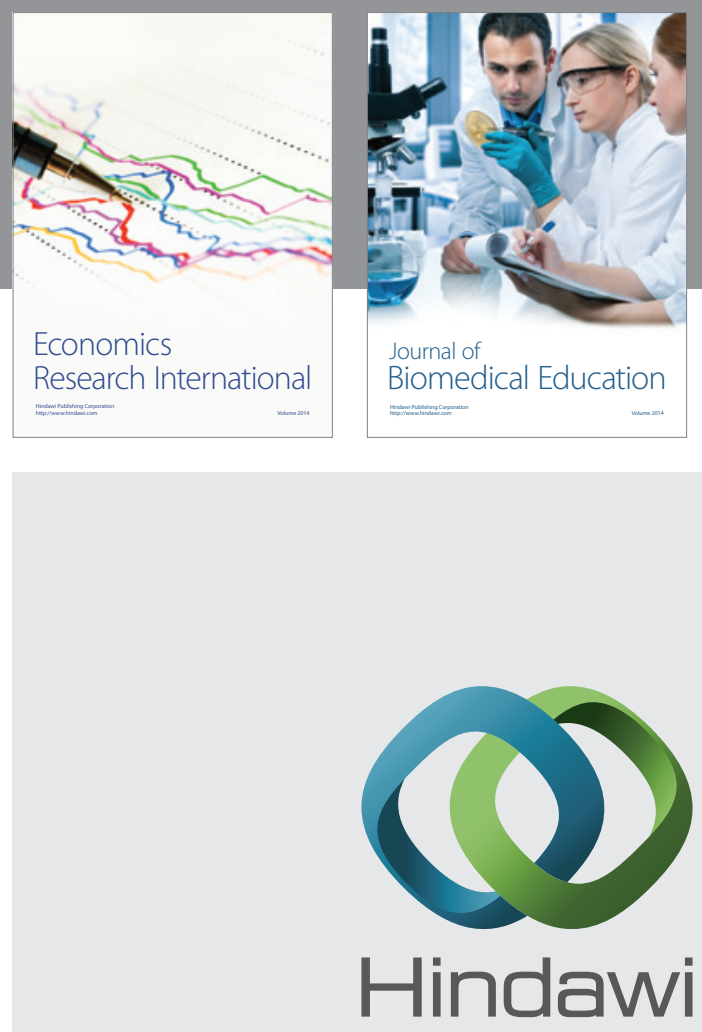

Submit your manuscripts at

http://www.hindawi.com
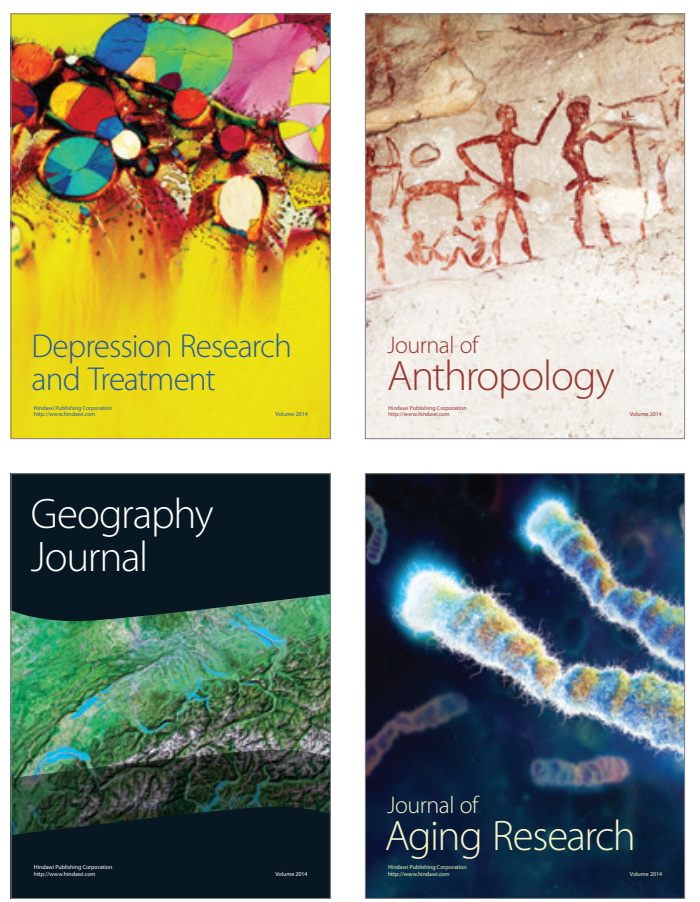
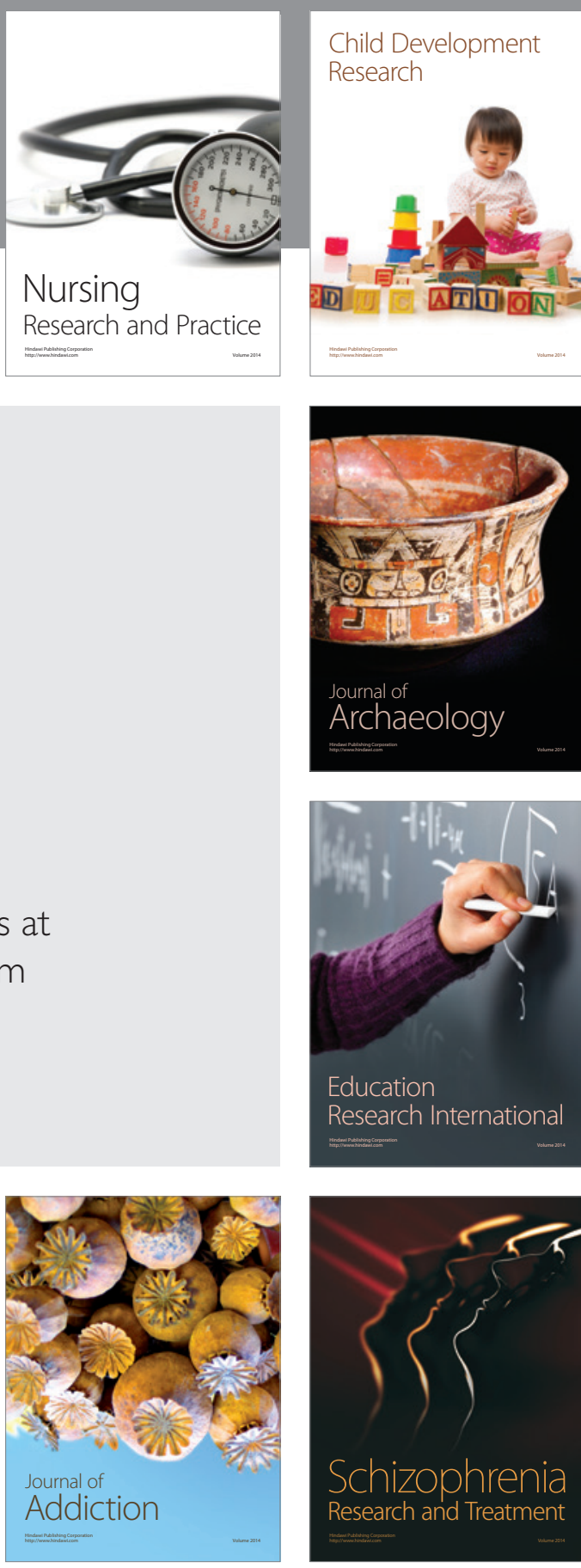

(D)
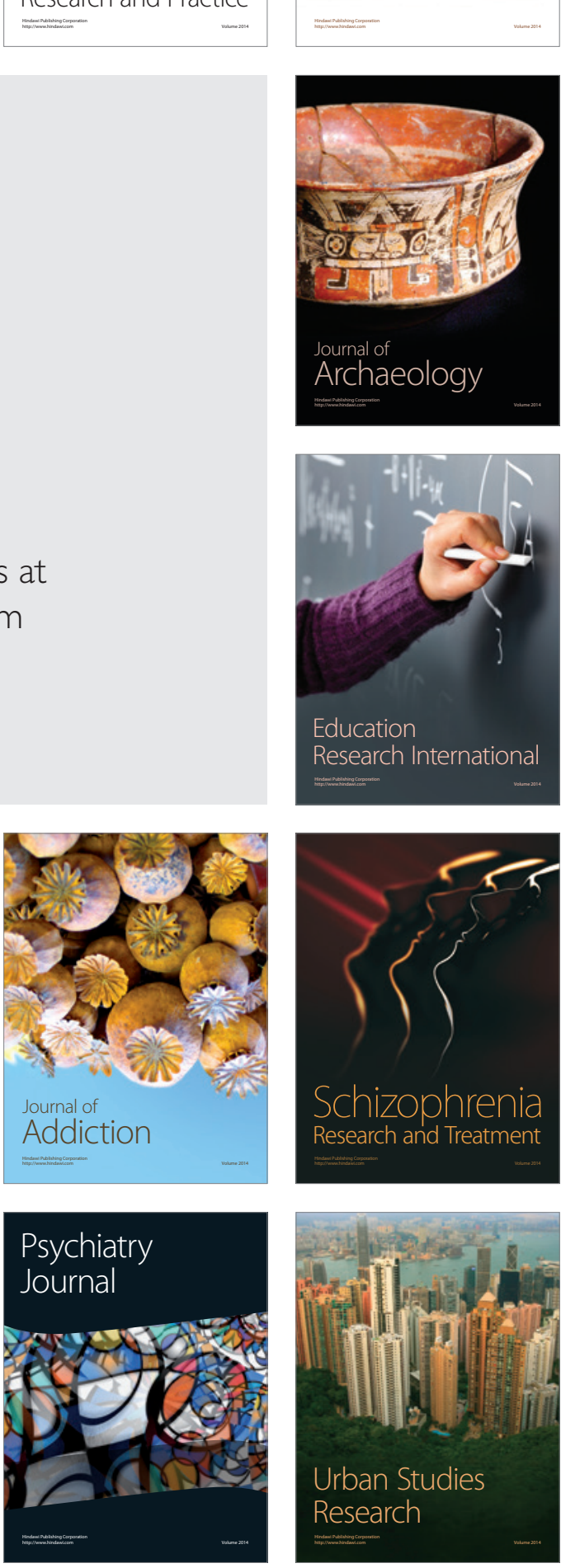